\title{
Invasive management without stents in selected acute coronary syndrome patients with a large thrombus burden: a prospective study of optical coherence tomography guided treatment decisions.
}

Souteyrand G, MD ${ }^{\mathrm{a}, \mathrm{b}}$; Amabile N, MD, $\mathrm{PhD}^{\mathrm{c}}$; Combaret N, MD ${ }^{\mathrm{a}, \mathrm{b}}$; Hammas S, $\mathrm{MD}^{\mathrm{c}}$; Prati F, MD, $\mathrm{PhD}^{\mathrm{d}}$; Berry C, MD $\mathrm{PhD}^{\mathrm{e}}$; Pereira B, $\mathrm{MD}^{\mathrm{f}}$, ;Lusson JR, MD, PhD ${ }^{\mathrm{a}, \mathrm{b}}$, Caussin C, $\mathrm{MD}^{\mathrm{c}}$; Motreff P, MD, $\mathrm{PhD}^{\mathrm{a}, \mathrm{b}}$.

${ }^{a}$ Department of Cardiology, Clermont-Ferrand University Hospital, Clermont-Ferrand, France.

${ }^{\mathrm{b}}$ Cardio Vascular Interventional Therapy and Imaging (CaVITI), Image Science for Interventional Techniques (ISIT), UMR CNRS 6284, Auvergne University, Clermont-Ferrand, France.

${ }^{\mathrm{c}}$ Department of Cardiology, Centre Marie Lannelongue, Le Plessis-Robinson, France.

${ }^{\mathrm{d}}$ Department of Interventional Cardiology, San Giovanni Hospital, Rome, Italy.

${ }^{\mathrm{e}}$ BHF Glasgow Cardiovascular Research Centre, Institute of Cardiovascular and Medical Sciences, University of Glasgow, and Golden Jubilee National Hospital, Glasgow, United Kingdom

${ }^{\mathrm{f}}$ Department of Clinical Research (DRCI), Biostatics Unit, Clermont-Ferrand University Hospital, Clermont-Ferrand, France.

Address for correspondence: Géraud SOUTEYRAND. Department of Cardiology, ClermontFerrand University Hospital, Clermont-Ferrand, France.

Phone: +33. 473751308

Email address: gsouteyrand@chu-clermontferrand.fr 


\section{STRUCTURED ABSTRACT}

Aims:

To assess whether a strategy of invasive management without stents in selected acute coronary syndrome (ACS) patients with a large thrombus burden (LTB) might be feasible and safe.

Methods and results:

We performed a prospective non-randomised observational cohort study of invasive treatment decisions guided by optical coherence tomography (OCT) in selected ACS patients with LTB. Among 852 ACS patients who had undergone invasive coronary angiography, 101(11.8\%) patients with large thrombus burden on initial angiography underwent thrombectomy to restore TIMI-3 flow without stenting. All of these patients then had repeat angiography with OCT (Day 0-2 (Group1), Day 3-6 (Group2) or Day 7-30 (Group3)).

No adverse events occurred between the initial and second angiograms. Residual thrombus was detected in $68 \%$ of patients with OCT (respectively, 94\%, $79 \%$ and $32 \%$ in Group1, Group2 and Group3) and 20\% of cases with angiography. Plaque rupture was detected by OCT in $65 \%$ of cases. Minimal lumen area was $2.81 \mathrm{~mm}^{2}, 3.40 \mathrm{~mm}^{2}$ and $4.89 \mathrm{~mm}^{2}$ in Group1, Group2 and Group3, respectively. 62\% of patients were stented (respectively, 76\%, 61\% and $50 \%$ ). During a minimum follow-up period of 12 months in all patients, 1 non-fatal MI occurred and 1 PCI was performed for angina.

\section{Conclusions:}

Medical management without stents is safe and feasible in selected ACS patients with LTB. OCT revealed culprit lesion characteristics that were not disclosed by angiography and facilitated treatment decisions. 


\section{KEY WORDS}

Acute coronary syndrome, optical coherence tomography, coronary thrombosis, myocardial infarction, percutaneous coronary intervention. 


\section{CONDENSED ABSTRACT}

We assessed the feasibility and safety of invasive management and selected stenting or not, as guided by angiography and OCT, in ACS patients with LTB. In a 2-stage strategy, angiography was used to select patients for delayed stenting, and in the second procedure angiography and OCT were used to decide on stenting or not. OCT improved the assessment of culprit lesion characteristics and thrombus burden. Of 101 STEMI patients, 38\% did not receive a stent. There were no adverse events related to OCT and only 2 non-fatal MACEs occurred during 12 months of follow-up. 


\section{ABBREVIATIONS LIST}

ACS : acute coronary syndrome

BMI : body mass index

BMS : bare metal stent

CPK : creatine phospho kinase

DES : drug eluting stent

IVUS : intravascular ultrasound

LAD : left anterior descending coronary artery

LCX : left circumflex

LMWH : low molecular weight heparin

LTB : large thrombus burden

LVEF : left ventricular ejection fraction

MACE : major adverse cardiac event

MLA : minimal lumen area

NSTEMI :non ST segment elevation myocardial infarction

OCT : optical coherence tomography

OFDI : optical frequency domain imaging

PCI : percutaneous coronary intervention

QCA : quantitative coronary angiography

RCA : right coronary artery

STEMI : ST segment elevation myocardial infarction

TIMI : thrombolysis in myocardial infarction 


\section{INTRODUCTION}

Early invasive management in patients with an acute coronary syndrome (ACS) is supported by evidence-based clinical guidelines ${ }^{1,2}$ guidelines and overall, prognosis has improved in recent years ${ }^{3}$. In ACS patient treated with PCI, stenting is almost always performed $^{4}$.

The purpose of stenting is to prevent acute vessel closure after reperfusion ${ }^{5}$. However, although stenting is routinely performed, stents can cause complications acutely (e.g. distal embolization, stent thrombosis) and in the longer term (e.g. restenosis and late/very late stent thrombosis). In ACS patients, coronary thrombus is a consequence of plaque rupture and persistent or large coronary thrombus (LCT) is a risk factor for adverse outcome after percutaneous coronary intervention (PCI) with stenting ${ }^{6}$. Stent deployment in a thrombotic lesion may dislodge thrombus leading to microcirculatory embolization with a no-reflow effect on reperfusion ${ }^{7}$, which is a cause of heart failure acutely and in the longer term. Furthermore, stent outcomes may be sub-optimal in thrombotic lesions due to malapposition of the stent on the coronary wall, and stent malapposition may also lead to adverse outcomes in the longer term. Large Thrombus Burden (LTB) (defined as a thrombus with length more than twice the diameter of the coronary artery by Sianos et al) is also associated with an increased risk of late stent thrombosis ${ }^{8}$. Reduction of thrombus burden during PCI improves procedure-related outcomes and is recommended in clinical guidelines. For example, the TAPAS study ${ }^{9}$ showed that mechanical thrombectomy improved myocardial blush and reduced the rate of 30-day major adverse cardiac events (MACE) ${ }^{10,11}$.

We questioned whether stenting could be safely avoided in selected patients with LTB and therefore potentially obviate the risk of complications associated with stenting. Given the emergence of new anti-thrombotic treatments and improved lesion assessment with intravascular imaging techniques, such as optical coherence tomography (OCT) ${ }^{12}$, we reasoned that stenting may not be mandated in all patients. OCT is a high-resolution $(10 \mu \mathrm{m})$ endocoronary imaging technique based on near-infrared light. It provides fine in vivo analysis of the 3-layer structure of the arterial wall $^{13}$, and of atherosclerotic lesions ${ }^{14}$ and highly sensitive thrombus detection ${ }^{15}$. OCT has been used since 2005 for imaging ACS-culprit lesions $^{16,17}$ and for immediate ${ }^{18}$ and late (neointimal cover ${ }^{19,20)}$ post-procedural stent followup. 
The present study concerned the feasibility, safety and clinical utility of OCT-guided treatment decisions in ACS patients during routine clinical practice. Our rationale was that detailed assessment of thrombus and culprit lesion characteristics by high-resolution endocoronary imaging could guide treatment decisions for coronary stenting after thrombus aspiration.

\section{MATERIAL AND METHODS}

\section{Methods}

\section{Eligible patients}

Between January 2010 and November 2011, 852 patients were admitted for ACS in two French hospital centers (Clermont-Ferrand University Hospital Center and Marie Lannelongue Surgical Center, Plessis-Robinson). One hundred and one ACS patients were included in the present observational study.

The inclusion criteria were the following:

- age $\geq 18$ years;

- STEMI or NSTEMI with high risk clinical characteristics including recurrent symptoms, tachycardia, hypotension or heart failure, according to European guidelines ${ }^{21}$;

- lEarge thrombus burden (thrombus length more than twice arterial diameter) on initial angiography, whatever the initial TIMI flow;

- $\underline{\mathrm{a} A}$ culprit coronary artery amenable to OCT imaging (including vessel diameter $<5 \mathrm{~mm}$ without significant tortuosity or calcification that might restrict the optical catheter).

The exclusion criteria were the following (at least 1):

- pregnancy or breast-feeding;

- contra-indication for glycoprotein (GP) IIb/IIIa inhibitor (abciximab, eptifibatide or tirofiban);

- admission for cardiac arrest;

- cardiogenic shock;

- known creatinine clearance $<30 \mathrm{ml} / \mathrm{min}$ 
All patients received treatment with $250 \mathrm{mg}$ of aspirin, a loading dose of clopidogrel (600 mg) or prasugrel $(10 \mathrm{mg}$ ) and therapeutic anti-coagulation (unfractionated (50/kg or low molecular weight heparin $(1 \mathrm{mg} / \mathrm{kg}))$.

\section{Protocol for treatment decisions}

A flow chart which summarizes the decision pathway is shown in Figure 1. The timing of the OCT procedure was at the operator's discretion during the first month after the acute phase.

\section{Medical management protocol}

The initial objective was to achieve optimal reperfusion by thrombus aspiration (Export Aspiration Catheter, Medtronic, Minneapolis, Minnesota) and treat the patients with optimal medical therapy including aspirin, a loading dose of clopidogrel or prasugrel and a bolus of abciximab in line with clinical guidelines ${ }^{1}$.

Optimal reperfusion was defined in presence of TIMI flow $=3$ associated with regression of pain and $>50 \%$ reduction in ST elevation at the post-intervention ECG.

Coronary stenting was indicated when 1 or more of these characteristics were absent. Alternatively, when optimal coronary reperfusion was achieved, the treatment decision (based on a second angiogram and OCT analysis) could, at the operator's discretion, be immediate or else postponed to allow time for the beneficial effects of optimal anti-thrombotic therapy, including dual anti-platelet therapy, glycoprotein IIbIIIa inhibitor therapy and anticoagulation with low molecular weight heparin.

Three study groups were defined according to the timing of repeat OCT imaging: Acute OCT (days 0-2), Early OCT (days 3-6) and Late OCT (days 7-30). The different time-points (acute, early and late) were pre-defined in order to assess the relationship between the interval from the initial angiogram (and duration of anti-thrombotic therapy) vs. culprit lesion morphology, as revealed by OCT.

The indication for a stent was based on a stenosis $>70 \%$ or plaque prolapse as revealed by OCT. The three criteria required to define plaque prolapse were (1) an appearance of a mobile plaque in continuity with the coronary wall with (2) evidence of plaque prolapse into the lumen and (3) a maximal plaque length exceeding one-third of the arterial diameter.

All patients received optimal medical therapy, and including some patients who did not receive a stent and instead received optimal medical therapy alone. 
When PCI with stenting was performed, OCT was used to assess the final stent result including for stent malapposition, defined as a strut/wall distance greater than the thickness of the strut (including polymer if any) ${ }^{22,23}$, significant intra-stent thrombotic protrusion (intraluminal tissue protrusion forming an arch between the stent struts ${ }^{22,23}$, considered moderate when less than and significant when more than $500 \mu \mathrm{m}$ thick) or proximal/distal edge dissection (upstream or downstream: edge dissection).

\section{Invasive management protocol}

The treatment decision algorithm is shown in Figure 1.

\section{Angiographic assessment criteria}

Angiographic measurements were taken in the Axis Siemens cathlab (Siemens Medical Solutions Inc., Malvern, Pennsylvania) after intracoronary injection of isosorbide dinitrate.

The following measurements were obtained: baseline TIMI flow, percentage stenosis on QCA (Quantitative Coronary Angiography: Siemens Quantcor, Siemens Medical Solutions), arterial reference segment diameter (mm), minimum arterial diameter (mm), and thrombus length (mm). For an occluded culprit artery, thrombus length was determined from the first angiogram after coronary reperfusion.

Angiographic analysis was performed by 2 independent investigators who were not involved in the clinical procedures. Disagreements were resolved by adjudication from a third observer.

\section{OCT assessment criteria}

The technique of OCT acquisitions (Frequency Domain OCT, version C7XR, St Jude Medical Inc., Saint Paul, Minnesota) was in line with recent expert review documents ${ }^{22,23}$.

OCT analysis focused on the presence of thrombus ${ }^{22,23}$; thrombus burden, based on its extension (thrombus area, longitudinal extension) and thrombus score ${ }^{22,23}$; reference segment lumen area; minimum lumen area; percentage area stenosis; and presence of plaque rupture or erosion. OCT analyses were performed by 2 independent investigators, specifically addressing the feasibility and interpretability of images of region of interest in each examination, and any procedure-related complications.

\section{Clinical assessment and follow-up}


Follow-up included screening for MACE (death, recurrence of myocardial infarction or need for surgical or percutaneous revascularization) and functional assessment (recurrence of angina) on systematic 12-months’ post-procedural consultation.

\section{Statistics}

Statistical analysis was performed using Stata software, version 12 (StataCorp, College Station, TX, US). The tests were two-sided, with a type I error set at $\alpha=0.05$. Quantitative parameters were presented as the mean \pm standard deviation (SD) for each group and as the number of patients and associated percentages for categorical variables. Comparisons between groups were analysed using the Chi-squared or Fisher's exact test for categorical variables followed by Marascuillo procedure, and by ANOVA or Kruskal-Wallis test (normality verified by Shapiro-Wilk test and homoscedasticity by Bartlett test) followed by appropriate post-hoc multiple comparisons test (Tukey-Kramer or Dunn) for quantitative variables. In second step, relations between different parameters and groups were improved considering the delay as a quantitative parameter (and not as three groups determined by clinical and statistical relevance). When appropriate, correlation coefficients (Pearson or Spearman) were used.

\section{RESULTS}

\section{Population}

Of 852 all comer ACS patients treated in our hospitals between 1 January 2010 to 1 November 2011, 101(11.8\%) patients (53 \pm 13 years, 78\% male; 94\% STEMI, 6\% NSTEMI) were included. These patients had a LTB in the culprit artery on initial angiography and were treated with aspiration thrombectomy. Twenty two percent of these patients were treated with pre-hospital thrombolysis. The clinical characteristics of the patients are shown in Table 1. Overall, 38 (38\%) patients did not receive a stent in the culprit lesion and were treated medically.

\section{Angiography results}

The results of the initial and subsequent angiograms are shown in Tables 1 and 2, respectively. OCT was performed at Days 0-2 (Group 1, including $n=18$ patients with immediate post-thrombectomy analysis), Days 3-6 (Group 2) or Days 7-30 (Group 3). Stenting was performed when the residual stenosis in the culprit lesion was $>70 \%$ of the reference area or when there was evidence of plaque prolapse. Clinical follow-up lasted for 12 months. 


\section{OCT results}

The OCT procedure was uncomplicated in all patients and all of the OCT recordings were of diagnostic quality (Table 3).

Thrombus was revealed in $68.3 \%$ with OCT and $20.8 \%$ of patients with angiography alone. Thrombus burden diminished over time and was revealed by OCT in $94.1 \%$ of patients in Group 1, 78.8\% of patients in Group 2 and 32.4\% of patients in Group 3, with mean thrombus scores of 21.6, 13.6 and 4.2, respectively. Thus, maximum thrombus area and length also diminished over time with sequential increases in minimum lumen area and reduced percentage stenosis across the groups. Mean lesion length was $13.5 \mathrm{~mm}$ and was less than $15 \mathrm{~mm}$ in $70 \%$ of cases.

Plaque rupture was disclosed by OCT in 66 patients (65.3\%) (Figure 2). In these cases, fibrous cap thickness ranged from 30 to $210 \mu \mathrm{m}$, for a median $73.6 \mu \mathrm{m}$. Plaque erosion was diagnosed in 25 patients in absence of thrombus or rupture : 22 of 25 patients with plaque erosion suspected were in the non immediate groups ( $n=7$ in the $G 2$ and $\mathbf{n = 1 5}$ in the G3). There were only 3 patients in the first group. In 10 other patients the shadow related to light attenuation by residual thrombus precluded diagnostic evaluation of the lesion: the diagnostic value of OCT is reduced in cases with red thrombus.

\section{Treatment and evolution}

The treatment and follow-up information are given in Table 3. All patients were treated by double anti-platelet therapy (DAP) and received low-molecular weight heparin anticoagulation during the initial hospital phase. LMWH was stopped when patients were discharged from the hospital. A total of 27 patients out of 101 were discharged from the hospital before the second angiography.

Only 63 patients (62.4\%) underwent coronary stenting and no complications occurred. The mean stent diameter was $3.40+/-0.6 \mathrm{~mm}$ and the mean length was $20.4+/-7.1 \mathrm{~mm}$. In all 63 patients, only 1 stent was implanted per lesion, including 9 with bifurcation lesions that had been managed by provisional T-stenting. The other 38 patients were managed medically. None required coronary artery bypass graft.

OCT was performed at the end of the procedure in all patients treated with PCI in order to assess the final stent results (Figure 3 ). There was evidence of limited $(<1 \mathrm{~mm})$ coronary edge dissection in 6 patients (9.5\%). Malapposition was observed in 11 patients (17.5\%) and intrastent protrusion in 45 (moderate $[<500 \mu \mathrm{m}]$ in 27 [48.5\%] and significant 
[>500 $\mu \mathrm{m}]$ in 18 [28.5\%]). Post-stent arterial reference area was $9.28+/-3.19 \mathrm{~mm}^{2}$, with a mean reference diameter of $3.32+/-0.75 \mathrm{~mm}$ and minimum arterial area of $7.51+/-3.52 \mathrm{~mm}^{2}$.

The peak serum CPK ranged from 93 to 8,695 IU, with a median of 1,257. The mean left ventricle ejection fraction measured by echocardiography was 56.2\% [37-80].

Two MACEs events occurred (2\%) during follow-up during 12 months follow-up. An 71 year old man who had been managed medically experienced angina and had a clinicallyindicated elective angiogram which showed culprit lesion progression which was treated with a drug-eluting stent. An 83 year old man managed by angioplasty, showed non-fatal ischemic ACS at 8 months post-procedure. There were no cases of sudden death or ef-myocardial infarction.

\section{DISCUSSION}

Our main finding is that using stratified management involving a staged approach with invasive management selectively guided by OCT combined with optimal anti-thrombotic therapy, nearly half of the ACS patients selected for this form of management were safely treated without a stent. In all, nearly $1 / 8^{\text {th }}$ of all-comer ACS patients in our hospitals were selected for this treatment pathway.

Our treatment algorithm was predicated on the use of optimal ant-thrombotic therapy to prevent coronary re-occlusion in patients who were not treated with a stent and high resolution intra-vascular imaging to stratify patients for stenting or not. We found that 1) sustained use of parenteral anti-thrombotic therapy was safe and not associated with bleeding problems, 2) staged repeated invasive management was safe, 3) OCT was feasible and safe in this setting, 3) OCT revealed thrombus burden and culprit lesion characteristics with superior resolution than angiography alone,4) OCT helped guide treatment decisions to stent or not (i.e. treat with medical therapy alone) and, 5) angiography underestimates thrombus burden, detecting $20.8 \%$ residual thrombus after thrombectomy, versus $68.3 \%$ on OCT.

Pathology studies by Virmani have shown that ACS are most often due to plaque rupture or erosion ${ }^{24}$; was and these observations have been subsequently confirmed on IVUS and on OCT ${ }^{24,26,27}$. Fibrous cap thickness is critical to onset of these complications, thickness $<65 \mu \mathrm{m}$ being associated with high risk of rupture ${ }^{28}$. The underlying stenosis is not necessarily tight, as the thrombotic component predominates in arterial occlusion. In case of LTB, stenting incurs a risk of no-flow, distal embolisation ${ }^{29,30}$ and malapposition. Kim, using 
$\mathrm{OCT}^{31}$, showed that late stent malapposition and neointimal coverage defect were observed more frequently in ACS than in chronic angina.

Historically, culprit lesion stenting has been the evidence-based standard of care for coronary artery disease amenable to PCI in ACS patients. However, several groups are reexamining this approach, and new treatment strategies are now emerging. Isaaz's ${ }^{32} 2$-step Minimalist Immediate Mechanical Intervention (MIMI) strategy consists in restoring TIMI-3 flow in the acute phase and postponing stenting from D0 to D2-5 to allow optimization of the result or indeed reconsideration of indications. The modernContemporary antithrombotic regime-therapy, including (glycoprotein IIb/IIIa inhibitor therapy, loading dose of -dual antiplatelet drugss, and anticoagulation $\left.{ }_{2}\right)$ allows such a wait-and-seefacilitates the safety of an observational approach, minimizing the risk of early thrombosis. Jolicoeur's recent metaanalysis $^{33}$ of 6 studies (5 non-randomized) found deferred stenting to be safe (3 coronary reocclusions before control, in 283 patients) and beneficial (improved LV function), with a lower 1-year MACE rate. The present study applied this 2-step strategy, with the interval to control (up to day 30) left at the operator's discretion while awaiting optimal thrombectomy using anti-GPIIb/IIIa and/or thrombo-aspiration as often as possible (respectively, $76.2 \%$ and 72.3\% of cases). Results confirmed the feasibility and safety of this attitude: in 101 patients, there were no MACEs before angiogram 2, taken at a mean 9 days (median, 5 days).

The presentOur study also confirmed that, in a setting of ACS, OCT was feasible, with no procedural complications in any of the 101 patients.; OCT-and provided consistently interpretable imagingdata. The new generation of OCT (OFDI: Optical Frequency Domain Imaging) is faster and easier simpler to perform ${ }^{34}$. OCT enables analysis not only of thrombus burden but also of the ACS-culprit lesion, for which Kubo ${ }^{15}$ demonstrated its superiority to angioscopy and IVUS: in this pilot study, OCT in the acute phase visualized thrombus in 100\% of cases, plaque rupture in $73 \%$ and erosion in 23\%. In 101 cases of ACS, the present study identified 66 plaque ruptures (65\% of cases) with a mean cap thickness of $73 \mu \mathrm{m}$, and 22 plaque erosions.

Finally, OCT can guide treatment, optimizing stenting and sometimes indicates isolated medical therapy. By sometimes postponing angiographic control, more complete thrombus regression can be obtained, with improved assessment of the atheromatous component of the stenosis. Previous works highlighted the negative impact of high thrombus burden within the culprit lesion on short and long-term outcome during STEMI ${ }^{35}$ or NSTEMI $^{36}$. Thrombectomy techniques can improve these results by dramatically reducing 
thrombus load during ACS, but a complete disappearance is rarely obtained and real benefits of the technique have been recently challenged ${ }^{37}$. Following thrombectomy, if there is no significant stenosis, the indication for stenting can be reviewed. Plaque erosion and with a moderate stenosis may show spontaneous eicatrization-healing, scar formation and reendothelialization of the arterial wall and: the favorable prognosis under optimal medical management seen onboth IVUS-in such cases $^{38}$ was recently confirmed onand OCT have provided information on plaque healing with medical therapyby Prati ${ }^{27}$. Thirty-eight of the present 101 patients were managed medically; without stenting, (38\%). At 12 months' followup, only 1 of the 38 showed evolution toward ischemic stenosis, requiring stenting at 6 months. In the series as a whole, there were no acute events (ACS or sudden death). Previous studies investigated the feasibility of deferred PCI for STEMI treatment under optimal antithrombotic therapy, on the basis of angiographic findings only ${ }^{39,40}$. These series reported that this procedure could be performed safely in selected patients and also induced a decreased rate of culprit lesion stenting. Hence, Echavarria-Pinto and colleagues observed that stenting could be avoided in $29.2 \%$ of their patients, which is comparable to the present data. However, the real impact of culprit lesion OCT analysis on the need for stent remains difficult to assess, as we do notsince our study did not include-have an angiography-only control group-of patients treated by angiography analysis alone, further randomised controlled studies are needed to assess the influence of OCT-guided treatment decisions for stenting or not of culprit lesions. This point was out of the range of the present pilot study but could be investigated in future randomized trials.

OCT-guided postponement eptimised stenting:of stent implantation was associated with good procedural outcomes: $100 \%$ success and no no-reflow events. The rate of malapposition was relatively low, at $17.5 \%$, despite ACS being a known factor for malapposition ${ }^{31}$. Thrombus reduction allows stent diameter and length to be tailored to the lesion, minimizing the risk of restenosis. The stents deployed were wider $(3.4+/-0.6 \mathrm{~mm})$ than initial QCA (mean reference diameter $-3.22+/ 0.59$ ) would have indicated. Finally, postponement reduced the rate of bifurcation stenting: initial angiography implicated bifurcations in 36\% of cases, whereas only $9 \%$ of patients actually needed bifurcation stenting.

What is the optimal interval for the OCT 'control' imaging in the 2-step management of ACS? Analyzing the 3 tertiles for the control imaging interval shows that thrombus burden tends to decrease over time on whatever criteria:according to thrombus length, maximum area or score. This reduction is associated with increased minimum lumen area and reduced 
percentage stenosis. This may account for the significantly reducedlower rate of stenting in the late-OCT group (Figure 4).

\section{Study limitations}

The main limitation of this study was the non-randomized design meaning we cannot draw conclusions about the influence of OCT over angiography alone on treatment decisions or clinical outcomes. Moreover the timing of OCT procedure was empirically decided by the operator until 1 month. Our study was neither designed nor powered for a health outcome analysis. The study population included selected patients during routine clinical care (approximately 15\% of all ACS cases admitted during the study period). Therefore, the conclusions in our study are relevant to patients with a large thrombus burden at initial angiography and should not be extrapolated to all-comer ACS patients especially where initial thrombus burden is light. Moreover, patients from Group 1 underwent early OCT analysis: although white thrombus (that induces minimal backscattering attenuation) was identified in the vast majority of the cases, residual large thrombus burden might have affected the analysis of the underlying plaque morphology. Hence, this factor could potentially explain the lowest incidence of plaque rupture/erosion identified in these patients compared to the others and advocates for the need of delaying the OCT control from the acute event in order to properly assess the underlying morphology of ACS culprit lesions._Finally, the appropriated OCT criteria to decide whether the culprit lesion should be stented or not are not validated in the settings ofin ACS and STEMIpatients remains to be determined. Importantly, overall, stenting of culprit lesions represents the overall standard of care. In our study, We used a ratio between reference lumen area and minimum lumen area (MLA) to tailor PCI.-use in this clinical situation that could be debatable.

Our proof-of-concept study was designed to assess feasibility and safety and a larger substantive trial will be needed to evaluate the role of OCT-guided treatment decisions in ACS patients with large thrombus burden. A randomised trial with surrogate health outcomes, such as with MRI for infarct size at 30 days, may be the next logical step.

\section{CONCLUSION}

OCT in ACS is feasible and complication-free. The present study demonstrated improved assessment of thrombus burden, which angiography tends to underestimate, and improved culprit-lesion analysis. 
Following maximal thrombectomy, OCT allowed abstention from stenting in 38\% of cases in this pilot study on a selected population. When indicated, stenting was reliable and perhaps better adapted to culprit-lesion morphology.

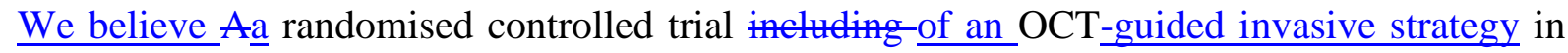
the management of ACS patients with LTB should determine the role of this technique in these indications. 


\section{REFERENCES}

1. Steg PG, James SK, Atar D, Badano LP, Blömstrom-Lundqvist C, Borger MA, Mario C Di, Dickstein K, Ducrocq G, Fernandez-Aviles F, Gershlick AH, Giannuzzi P, Halvorsen S, Huber K, Juni P, Kastrati A, Knuuti J, Lenzen MJ, Mahaffey KW, Valgimigli M, Hof A van 't, Widimsky P, Zahger D. ESC Guidelines for the management of acute myocardial infarction in patients presenting with ST-segment elevation. Eur Heart J. 2012;33:2569-2619.

2. Kushner FG, Hand M, Smith SC Jr, King SB 3rd, Anderson JL, Antman EM, Bailey SR, Bates ER, Blankenship JC, Casey DE Jr, Green LA, Hochman JS, Jacobs AK, Krumholz HM, Morrison DA, Ornato JP, Pearle DL, Peterson ED, Sloan MA, Whitlow PL, Williams DO. 2009 focused updates: ACC/AHA guidelines for the management of patients with ST-elevation myocardial infarction (updating the 2004 guideline and 2007 focused update) and ACC/AHA/SCAI guidelines on percutaneous coronary intervention (updating the 2005 guideline and 2007 focused update) a report of the American College of Cardiology Foundation/American Heart Association Task Force on Practice Guidelines. J Am Coll Cardiol. 2009;54:2205-2241.

3. Puymirat E, Simon T, Steg PG, Schiele F, Guéret P, Blanchard D, Khalife K, Goldstein P, Cattan S, Vaur L, Cambou J-P, Ferrières J, Danchin N. Association of changes in clinical characteristics and management with improvement in survival among patients with ST-elevation myocardial infarction. Jama J Am Med Assoc. 2012;308:998-1006.

4. Grines CL, Cox DA, Stone GW, Garcia E, Mattos LA, Giambartolomei A, Brodie BR, Madonna O, Eijgelshoven M, Lansky AJ, O’Neill WW, Morice MC. Coronary angioplasty with or without stent implantation for acute myocardial infarction. Stent Primary Angioplasty in Myocardial Infarction Study Group. $N$ Engl J Med. 1999;341:1949-1956.

5. Degeare VS, Dangas G, Stone GW, Grines CL. Interventional procedures in acute myocardial infarction. Am Heart J. 2001;141:15-24.

6. Singh M, Berger PB, Ting HH, Rihal CS, Wilson SH, Lennon RJ, Reeder GS, Bresnahan JF, Holmes Jr. DR. Influence of coronary thrombus on outcome of percutaneous coronary angioplasty in the current era (the Mayo Clinic experience). Am J Cardiol. 2001;88:1091-1096.

7. White CJ, Ramee SR, Collins TJ, Escobar AE, Karsan A, Shaw D, Jain SP, Bass TA, Heuser RR, Teirstein PS, Bonan R, Walter PD, Smalling RW. Coronary thrombi increase PTCA risk. Angioscopy as a clinical tool. Circulation. 1996;93:253-258.

8. Sianos G, Papafaklis MI, Daemen J, Vaina S, Mieghem CA van, Domburg RT van, Michalis LK, Serruys PW. Angiographic stent thrombosis after routine use of drugeluting stents in ST-segment elevation myocardial infarction: the importance of thrombus burden. J Am Coll Cardiol. 2007;50:573-583. 
9. Svilaas T, Vlaar PJ, Horst IC van der, Diercks GFH, Smet BJGL de, Heuvel AFM van den, Anthonio RL, Jessurun GA, Tan E-S, Suurmeijer AJH, Zijlstra F. Thrombus aspiration during primary percutaneous coronary intervention. $N$ Engl J Med. 2008;358:557-567.

10. Cook S, Wenaweser P, Togni M, Billinger M, Morger C, Seiler C, Vogel R, Hess O, Meier B, Windecker S. Incomplete stent apposition and very late stent thrombosis after drug-eluting stent implantation. Circulation. 2007;115:2426-2434.

11. Cook S, Eshtehardi P, Kalesan B, Räber L, Wenaweser P, Togni M, Moschovitis A, Vogel R, Seiler C, Eberli FR, Lüscher T, Meier B, Jüni P, Windecker S. Impact of incomplete stent apposition on long-term clinical outcome after drug-eluting stent implantation. Eur Heart J [Internet]. 2012 [cited 2012 May 13]; Available from: http://www.ncbi.nlm.nih.gov/pubmed/22285579

12. Barlis P, Gonzalo N, Mario C Di, Prati F, Buellesfeld L, Rieber J, Dalby MC, Ferrante G, Cera M, Grube E, Serruys PW, Regar E. A multicentre evaluation of the safety of intracoronary optical coherence tomography. Eurointervention J Eur Collab Work Group Interv Cardiol Eur Soc Cardiol. 2009;5:90-95.

13. Kume T, Akasaka T, Kawamoto T, Watanabe N, Toyota E, Neishi Y, Sukmawan R, Sadahira Y, Yoshida K. Assessment of coronary intima--media thickness by optical coherence tomography: comparison with intravascular ultrasound. Circ J Off J Jpn Circ Soc. 2005;69:903-907.

14. Yabushita H, Bouma BE, Houser SL, Aretz HT, Jang I-K, Schlendorf KH, Kauffman CR, Shishkov M, Kang D-H, Halpern EF, Tearney GJ. Characterization of human atherosclerosis by optical coherence tomography. Circulation. 2002;106:1640-1645.

15. Kubo T, Imanishi T, Takarada S, Kuroi A, Ueno S, Yamano T, Tanimoto T, Matsuo Y, Masho T, Kitabata H, Tsuda K, Tomobuchi Y, Akasaka T. Assessment of culprit lesion morphology in acute myocardial infarction: ability of optical coherence tomography compared with intravascular ultrasound and coronary angioscopy. J Am Coll Cardiol. 2007;50:933-939.

16. Jang I-K, Tearney GJ, MacNeill B, Takano M, Moselewski F, Iftima N, Shishkov M, Houser S, Aretz HT, Halpern EF, Bouma BE. In vivo characterization of coronary atherosclerotic plaque by use of optical coherence tomography. Circulation. 2005;111:1551-1555.

17. Kubo T, Ino Y, Tanimoto T, Kitabata H, Tanaka A, Akasaka T. Optical coherence tomography imaging in acute coronary syndromes. Cardiol Res Pr. 2011;2011:312978.

18. Bouma BE, Tearney GJ, Yabushita H, Shishkov M, Kauffman CR, DeJoseph Gauthier D, MacNeill BD, Houser SL, Aretz HT, Halpern EF, Jang I-K. Evaluation of intracoronary stenting by intravascular optical coherence tomography. Heart Br Card Soc. 2003;89:317-320.

19. Chen BX, Ma FY, Luo W, Ruan JH, Xie WL, Zhao XZ, Sun SH, Guo XM, Wang F, Tian T, Chu XW. Neointimal coverage of bare-metal and sirolimus-eluting stents evaluated with optical coherence tomography. Heart Br Card Soc. 2008;94:566-570. 
20. Yao Z, Matsubara T, Inada T, Suzuki Y, Suzuki T. Neointimal coverage of sirolimuseluting stents 6 months and 12 months after implantation: evaluation by optical coherence tomography. Chin Med J (Engl). 2008;121:503-507.

21. Hamm CW, Bassand J-P, Agewall S, Bax J, Boersma E, Bueno H, Caso P, Dudek D, Gielen S, Huber K, Ohman M, Petrie MC, Sonntag F, Uva MS, Storey RF, Wijns W, Zahger D, Bax JJ, Auricchio A, Baumgartner H, Ceconi C, Dean V, Deaton C, Fagard R, Funck-Brentano C, Hasdai D, Hoes A, Knuuti J, Kolh P, McDonagh T, et al. ESC Guidelines for the management of acute coronary syndromes in patients presenting without persistent ST-segment elevation: The Task Force for the management of acute coronary syndromes (ACS) in patients presenting without persistent ST-segment elevation of the European Society of Cardiology (ESC). Eur Heart J. 2011;32:29993054.

22. Prati F, Guagliumi G, Mintz GS, Costa M, Regar E, Akasaka T, Barlis P, Tearney GJ, Jang I-K, Arbustini E, Bezerra HG, Ozaki Y, Bruining N, Dudek D, Radu M, Erglis A, Motreff P, Alfonso F, Toutouzas K, Gonzalo N, Tamburino C, Adriaenssens T, Pinto F, Serruys PWJ, Mario C Di. Expert review document part 2: methodology, terminology and clinical applications of optical coherence tomography for the assessment of interventional procedures. Eur Heart J. 2012;33:2513-2520.

23. Tearney GJ, Regar E, Akasaka T, Adriaenssens T, Barlis P, Bezerra HG, Bouma B, Bruining N, Cho J, Chowdhary S, Costa MA, Silva R de, Dijkstra J, Mario C Di, Dudeck D, Falk E, Feldman MD, Fitzgerald P, Garcia H, Gonzalo N, Granada JF, Guagliumi G, Holm NR, Honda Y, Ikeno F, Kawasaki M, Kochman J, Koltowski L, Kubo T, Kume T, et al. Consensus standards for acquisition, measurement, and reporting of intravascular optical coherence tomography studies: a report from the International Working Group for Intravascular Optical Coherence Tomography Standardization and Validation. J Am Coll Cardiol. 2012;59:1058-1072.

24. Virmani R, Burke AP, Farb A, Kolodgie FD. Pathology of the Vulnerable Plaque. $J$ Am Coll Cardiol. 2006;47:C13-C18.

25. Akasaka T, Kubo T, Mizukoshi M, Tanaka A, Kitabata H, Tanimoto T, Imanishi T. Pathophysiology of acute coronary syndrome assessed by optical coherence tomography. J Cardiol. 2010;56:8-14.

26. Regar E, Soest G van, Bruining N, Constantinescu AA, Geuns RJ van, Giessen W van der, Serruys PW. Optical coherence tomography in patients with acute coronary syndrome. Eurointervention J Eur Collab Work Group Interv Cardiol Eur Soc Cardiol. 2010;6 Suppl G:G154-160.

27. Prati F, Uemura S, Souteyrand G, Virmani R, Motreff P, Vito L Di, Biondi-Zoccai G, Halperin J, Fuster V, Ozaki Y, Narula J. OCT-Based Diagnosis and Management of STEMI Associated With Intact Fibrous Cap. Jacc Cardiovasc Imaging. 2013;6:283-287.

28. Vengrenyuk Y, Carlier S, Xanthos S, Cardoso L, Ganatos P, Virmani R, Einav S, Gilchrist L, Weinbaum S. A Hypothesis for Vulnerable Plaque Rupture Due to StressInduced Debonding Around Cellular Microcalcifications in Thin Fibrous Caps. Proc Natl Acad Sci. 2006;103:14678-14683. 
29. Henriques JPS, Zijlstra F, Ottervanger JP, Boer M-J de, Hof AWJ van 't, Hoorntje JCA, Suryapranata H. Incidence and clinical significance of distal embolization during primary angioplasty for acute myocardial infarction. Eur Heart J. 2002;23:1112-1117.

30. Claeys MJ, Bosmans J, Veenstra L, Jorens P, Raedt HD, Vrints CJ. Determinants and Prognostic Implications of Persistent ST-Segment Elevation After Primary Angioplasty for Acute Myocardial Infarction Importance of Microvascular Reperfusion Injury on Clinical Outcome. Circulation. 1999;99:1972-1977.

31. Kim J-S, Fan C, Choi D, Jang I-K, Lee JM, Kim TH, Park SM, Paik S il, Ko Y-G, Hong M-K, Jang Y, Chung N. Different patterns of neointimal coverage between acute coronary syndrome and stable angina after various types of drug-eluting stents implantation; 9-month follow-up optical coherence tomography study. Int J Cardiol. 2011;146:341-346.

32. Isaaz K, Robin C, Cerisier A, Lamaud M, Richard L, Costa A Da, Sabry MH, Gerenton C, Blanc JL. A new approach of primary angioplasty for ST-elevation acute myocardial infarction based on minimalist immediate mechanical intervention. Coron Artery Dis. 2006;17:261-269.

33. Freixa X, Belle L, Joseph L, Tanguay J-F, Souteyrand G, L Allier PL, Jolicœur EM. Immediate vs. delayed stenting in acute myocardial infarction: a systematic review and meta-analysis. Eurointervention J Eur Collab Work Group Interv Cardiol Eur Soc Cardiol. 2013;8:1207-1216.

34. Takarada S, Imanishi T, Liu Y, Ikejima H, Tsujioka H, Kuroi A, Ishibashi K, Komukai K, Tanimoto T, Ino Y, Kitabata H, Kubo T, Nakamura N, Hirata K, Tanaka A, Mizukoshi M, Akasaka T. Advantage of next-generation frequency-domain optical coherence tomography compared with conventional time-domain system in the assessment of coronary lesion. Catheter Cardiovasc Interv Off J Soc Card Angiogr Interv. 2010;75:202-206.

35. Sianos G, Papafaklis MI, Daemen J, Vaina S, van Mieghem CA, van Domburg RT, Michalis LK, Serruys PW. Angiographic stent thrombosis after routine use of drugeluting stents in st-segment elevation myocardial infarction: the importance of thrombus burden. J Am Coll Cardiol. 2007;50:573-83.

36. Goto K, Lansky AJ, Nikolsky E, Fahy M, Feit F, Ohman EM, White HD, Mehran R, Bertrand ME, Desmet W, Hamon M, Stone GW. Prognostic significance of coronary thrombus in patients undergoing percutaneous coronary intervention for acute coronary syndromes: a subanalysis of the acuity (acute catheterization and urgent intervention triage strategy) trial. JACC: Cardiovascular Interventions. 2011;4:769-77.

37. Frobert O, Lagerqvist B, Olivecrona GK, Omerovic E, Gudnason T, Maeng M, Aasa M, Angerås O, Calais F, Danielewicz M, Erlinge D, Hellsten L, Jensen U, Johansson AC, Kåregren A, Nilsson J, Robertson L, Sandhall L, Sjögren I, Ostlund O, Harnek J, James SK. Thrombus aspiration during st-segment elevation myocardial infarction. $N$ Engl $J$ Med. 2013;369:1587-97. 
38. Rioufol G, Gilard M, Finet G, Ginon I, Boschat J, André-Fouët X. Evolution of spontaneous atherosclerotic plaque rupture with medical therapy: long-term follow-up with intravascular ultrasound. Circulation. 2004;110:2875-2880.

39. Escaned J, Echavarría-Pinto M, Gorgadze T, Gonzalo N, Armengol F, Hernández R, Jiménez-Quevedo P, Nuñez-Gil IJ, Pérez-Vizcayno MJ, Alfonso F, Bañuelos C, Ibañez B, García E, Fernández-Ortiz A, Macaya C. Safety of Lone Thrombus Aspiration Without Concomitant Coronary Stenting in Selected Patients with Acute Myocardial Infarction. EuroIntervention. 2013;8:1149-56.

40. Echavarría-Pinto M, Lopes R, Gorgadze T, Gonzalo N, Hernández R, Jiménez-Quevedo P, Alfonso F, Bañuelos C, Nuñez-Gil IJ, Ibañez B, Fernández C, Fernandez-Ortiz A, García E, Macaya C, Escaned J. Safety and Efficacy of Intense Antithrombotic Treatment and Percutaneous Coronary Intervention Deferral in Patients with Large Intracoronary Thrombus. Am J Cardiol. 2013;111:1745-50. 


\section{Figure legends}

Figure 1: Decision and treatment tree

Figure 2 : Five examples of young patients ( $<50$ years) included in the study: angiographies (A,B,C,D,E) at baseline (top) and after thrombectomy (bottom); OCT frames after thrombectomy (A',B',C’,D’,E’) of the culprit lesion (top) and reference segment (bottom). Only C, D and E were stented, for residual stenosis $>70 \%$ or plaque prolapse.

Figure 3 : Baseline angiography (A) in a 37 year-old female treated by thrombus aspiration and GPIIb/IIIa inhibitors. Angiography 30 days later, before (B) and after stenting (C). OCT frames of culprit lesion (B1) and reference segment (B2), minimum lumen area (MLA) <30\% reference lumen area (RLA). Post-stenting OCT frames showing optimal strut apposition without thrombus protrusion (C1).

Figure 4: Thrombotic score (gray boxes) and stenting rate (white boxes) in each group: acute (D0 to D2), early (D3 to D6) and late OCT (D7 to D30). 